\title{
Robotic transanal surgery: perspectives for application
}

\author{
Pietro Genova ${ }^{1}$, Riccardo Memeo $^{2}$, Francesco Brunetti ${ }^{3}$ \\ 'Department of Surgical, Oncological and Oral Sciences (Di.Chir.On.S.), Paolo Giaccone University Hospital, University of \\ Palermo, Palermo 90127, Italy. \\ ${ }^{2}$ Department of Emergency and Organ Transplantation, Institute of General Surgery and Liver Transplantation, University of \\ Bari, Bari 70124, Italy. \\ ${ }^{3}$ Department of Digestive and Hepato-Pancreato-Biliary Surgery, Henri Mondor University Hospital, AP-HP, Université Paris- \\ Est Créteil (UPEC), Créteil 94010, France.
}

Correspondence to: Dr. Pietro Genova, Department of Surgical, Oncological and Oral Sciences (Di.Chir.On.S.), Paolo Giaccone University Hospital, University of Palermo, Via del Vespro 129, Palermo 90127, Italy. E-mail: pietro.genova@gmail.com

How to cite this article: Genova P, Memeo R, Brunetti F. Robotic transanal surgery: perspectives for application. Mini-invasive Surg 2020;4:20. http://dx.doi.org/10.20517/2574-1225.2019.47

Received: 30 Oct 2019 First Decision: 3 Feb 2020 Revised: 27 Feb 2020 Accepted: 4 Mar 2020 Published: 13 Mar 2020

Science Editor: Giulio Belli Copy Editor: Jing-Wen Zhang Production Editor: Tian Zhang

\begin{abstract}
Transanal minimally invasive surgery (TAMIS) is a surgical technique which allows the local excision of rectal benign tumors and early stage cancers measuring up to $4 \mathrm{~cm}$ and lying within $6-8 \mathrm{~cm}$ from the anal verge. It is performed by means of a disposable transanal platform and conventional laparoscopic instruments, proving to be effective and easily available. Hence, TAMIS soon became a valid alternative to other transanal resective procedures, especially transanal endoscopic microsurgery, and rapidly spread. Moreover, soon after its introduction, TAMIS started to be performed also using robotic technologies, but no clear advantages were found to date. This review is intended to provide a general overview on TAMIS, with a special focus on its association with robotic systems and the perspectives of this approach.
\end{abstract}

Keywords: Transanal minimally invasive surgery, robotic transanal minimally invasive surgery, robotic transanal surgery

\section{INTRODUCTION}

Benign tumors and early stage cancers of the rectum measuring less than $4 \mathrm{~cm}$ and lying within 6-8 $\mathrm{cm}$ from the anal verge represented for a long time an indication for conventional transanal excision (TAE) $)^{[1]}$. This technique was performed under direct view using a rigid anoscope and conventional surgical instruments. However, inadequate exposure was quite usual, especially when lesions were located in the middle or 
upper rectum, which frequently appeared inaccessible ${ }^{[1,2]}$. That often compromised the quality of surgical resection $^{[1,2]}$, with a rate of positive margins higher than $10 \%$ even in the series of the most experienced surgeons ${ }^{[3,4]}$.

The attempt to overcome the limitations of TAE stimulated the development of transanal endoscopic microsurgery (TEM). Introduced in the early 1980 s by Buess et al. ${ }^{[5]}$, this technique involved the use of three main components: a specific rigid proctoscope, a dedicated camera, and modified laparoscopic instruments. In particular, the rigid proctoscope was fixed to the operating table, oriented by the surgeon, and provided with several ports for pneumorectum creation, smoke evacuation, the camera, and instruments. Operative steps were quite similar to TAE, and the surgical wound resulting from full- or partial-thickness wall resection could be left open or closed by several techniques (such as sutures or clips).

Compared to TAE, TEM allowed an easier resection of rectal tumors lying in the middle or upper rectum, making excision possible even in some cases of lower sigmoid colon lesion ${ }^{[6]}$. Moreover, several studies showed better outcomes after $\mathrm{TEM}^{[3,7-10]}$. Notably, a systematic review with meta-analysis published by Clancy et al. ${ }^{[8]}$ in 2015 reported significant differences in terms of negative resection margins, specimen fragmentation, and local recurrence in favor of TEM, whereas the postoperative complication rate was similar between conventional TEM and TAE.

However, TEM showed to have some important limitations. Notably, the dedicated surgical equipment was designed for an up-to-down approach to rectal lumen. That made the resection of anterior rectal lesions quite challenging, requiring to place the patient in a prone position and to use specific split-leg operating tables. Moreover, the necessary surgical material was expensive and the learning curve long. Hence, the implementation of TEM remained limited ${ }^{[1,2]}$.

To provide an alternative to TEM for local excision of rectal tumors, in 2009, an American surgical team from Florida introduced a new technique called transanal minimally invasive surgery (TAMIS ${ }^{[1]]}$.

The present study is intended to provide a general overview on TAMIS, summarizing its most important aspects and focusing on the association with robotic technology and its implementation.

\section{TAMIS: TECHNICAL ASPECTS AND INDICATIONS}

TAMIS is a surgical technique introduced by Atallah, Albert, and Larach in 2009 to provide an alternative to TEM for local excision of rectal neoplasia ${ }^{[11]}$.

It combines the use of a disposable multichannel port placed transanally with conventional laparoscopic equipment. Notably, the pneumorectum is achieved using common laparoscopic systems inflating $\mathrm{CO}_{2}$, and the endoluminal pressure ranges between 15 and $25 \mathrm{mmHg}^{[1]}$. A $30^{\circ}$ - or $45^{\circ}$-angled $5-\mathrm{mm}$ laparoscope is preferable ${ }^{[12,13]}$, whereas conventional laparoscopic instruments are used for manipulation. Initially, singlesite multichannel ports conceived for laparoscopic abdominal surgery were adapted to a transanal use. Later, several devices were specifically designed ${ }^{[12-14]}$.

TAMIS is indicated for the local excision of a number of benign and premalignant tumors of the rectum located at up to $15 \mathrm{~cm}$ from the anal verge ${ }^{[15-19]}$. This technique may also represent a curative treatment for selected patients with rectal cancer. Notably, according to the National Comprehensive Cancer Network guidelines $2018^{[20]}$, transanal local excision may be an appropriate therapeutic option in case of early-stage T1 tumors with small size $(<3 \mathrm{~cm})$, well to moderate differentiation, location within $8 \mathrm{~cm}$ from the anal verge, and extension to less than $30 \%$ of rectal circumference. The resection must be full-thickness and assure more than $3-\mathrm{mm}$ negative margins. The specimen must be oriented and pinned before fixation. In the 
case of negative pathological features, such as positive resection margins, lymphatic and vascular invasion, poor differentiation, or Kikuchi sm3 level, a more radical resection is needed. Moreover, TAMIS could also be indicated in the case of more advanced T-stage rectal cancer in order to provide an excisional biopsy for a more precise pathologic examination or to treat patients at high surgical risk in association with other treatments ${ }^{[13,14]}$.

The principles of local resection are similar in TEM and TAMIS. First, the lesion must be marked around its circumference. Benign tumors may be excised limiting the dissection to the submucosal layer, without need to close the surgical wounds ${ }^{[13]}$. On the contrary, malignant tumors require a full-thickness resection of the rectal wall ${ }^{[13]}$. Moreover, in the case of posterior tumors, a small amount of perirectal fat may be excised en bloc to ensure a complete excision and allow lymph node analysis ${ }^{[13]}$.

When rectal tumors are located posteriorly, it would not be necessary to close a full-thickness defect because of its extraperitoneal position, as suggested by several authors reporting no higher complication rate after leaving surgical wounds open ${ }^{[13,21]}$. However, this time-consuming practice is recommended to cover an eventual peritoneal entry ${ }^{[13,22]}$. In particular, the wall defect is generally closed transversely, using separated or running sutures, clips, or other devices ${ }^{[1,13]}$. Peritoneal entry represents a well-known complication of TAMIS and it is described more frequently when tumors are located anteriorly in the middle or upper rectum ${ }^{[12]}$. When it occurs ( $1 \%$ of cases $\left.^{[12]}\right)$, it is recommended to use a steep Trendelenburg position to facilitate wall repair and to convert to laparoscopy if it is impossible to maintain an adequate pneumorectum ${ }^{[22-24]}$. With this regard, some authors suggest placing the patients in a prone position to limit the amount of $\mathrm{CO}_{2}$ passing into the peritoneal cavity ${ }^{[25]}$. Among the postoperative complications of TAMIS, a rectovaginal fistula can also occur, besides common general surgery complications, such as bleeding $(2.8 \%)^{[12]}$, fever, urinary tract infections, and atrial fibrillation.

\section{TAMIS: OUTCOMES}

In 2014, Martin-Perez et al. ${ }^{[12]}$ published a systematic review of the literature about TAMIS, including 24 retrospective studies and 9 case reports. The authors reported that up to eight alternative abbreviations were used to indicate the same technique, and included overall 390 patients, undergoing TAMIS for malignant lesions in 209 cases (53.5\%), adenomas and high-grade dysplasia in 152 cases (39\%), and other pathology in 29 cases (7.5\%). Among these latter 29 cases, 23 patients (79.3\%) were operated for neuroendocrine lesions, 3 patients (10.3\%) for fibrosis, 1 patient (3\%) for GIST, 1 patient (3\%) for mucocele, and 1 patient (3\%) for melanoma. Surgical procedures were performed using eight different TAMIS platforms, among which SILS port was the most commonly used (66.7\% of all studies included). The mean size of resected lesions was $3.1 \mathrm{~cm}$ (range: $0.8-4.7 \mathrm{~cm}$ ), whereas the mean distance from the anal verge was $7.6 \mathrm{~cm}$ (range: $3-15 \mathrm{~cm}$ ). The authors reported only full-thickness excisions in 22 studies $(60.6 \%)$, only partial thickness excisions in 3 studies, both full-thickness and partial thickness excisions in 8 studies (24.2\%), and no precision about the extent of resection in 5 studies (15.2\%). Conversion rate to TAE, TEM, or abdominal laparoscopic surgery was $2.31 \%$ (9/390). The mean operative time was 76 min (range 25-162 min), the complication rate was $7.4 \%$, and the mean hospital stay was two days. Considering the publications reporting specific information about surgical resection quality, the rates of positive resection margins, specimen fragmentation, and recurrence were $4.36 \%(12 / 275), 4.1 \%(4 / 97)$, and $2.7 \%(7 / 259)$, respectively.

\section{TAMIS VS. TEM}

In the literature, several studies compared the outcomes of TAMIS and TEM ${ }^{[26-28]}$. Among them, it is important to consider the large multi-institutional matched prospective study published by Lee et al. ${ }^{[28]}$ in 2017. It included 181 patients undergoing TAMIS and 247 patients undergoing TEM, and showed that 
TAMIS was associated with shorter operative time (mean: $70 \mathrm{~min} v s .108 \mathrm{~min}$ ), shorter length of hospital stay (median: zero days vs. one day), and lower blood loss (median: $10 \mathrm{~mL} v \boldsymbol{s} .30 \mathrm{~mL}$ ) compared to TEM. However, no significant difference was found in terms of positive margins (7\% for TAMIS vs. $6 \%$ for TEM), specimen fragmentation ( $4 \%$ for TAMIS $v$ s. $3 \%$ for TEM), postoperative complications ( $9 \%$ for TAMIS $v$ s. $11 \%$ for TEM), and recurrence after resection for rectal malignant lesion (7\% for TAMIS $v$ s. $7 \%$ for TEM). Overall, the authors concluded that, given the absence of significant differences in terms of resection quality and postoperative morbidity, the choice of the technique should be based on surgeon's preference, availability of surgical materials, and costs.

Two further comparative studies were both published in $2016^{[26,27]}$. Notably, compared to TEM, TAMIS had shorter median hospital stay (four days $v s$. five days) but lower full-thickness resection rate ( $85 \% v s$. $100 \%$ ) according to Mege et al. ${ }^{[26]}$ and higher specimen volume (mean: $5.6 \mathrm{~cm}^{3} v$ s. $15.9 \mathrm{~cm}^{3}$ ) according to Melin et al. ${ }^{[27]}$. No other significant difference between TAMIS and TEM was found in terms of operative, pathological, and survival outcomes.

In 2019, Van den Eynde et al. ${ }^{[2]}$ published another retrospective comparative study, including 68 patients in the group TAMIS and 53 patients in the group TEM. No conversion was reported in both groups. Operative time was again significantly shorter for TAMIS (median: $45 \mathrm{~min} v s .65 \mathrm{~min}$ ), whereas lesion surface area was larger for TEM (median: $21 \mathrm{~cm}^{2} v s .14 \mathrm{~cm}^{2}$ ). The difference in operative time persisted after correction for lesion surface area. No other significant difference was found in terms of quality of resection, morbidity, and hospital stay. Finally, the authors concluded in favor of TAMIS, whose shorter hospital stay was explained by an easier set-up and a greater versatility of the transanal platform. Moreover, the main advantage of TAMIS was identified in the fact that all procedures could be performed in lithotomy position, the whole rectal circumference being accessible with this technique.

To be noted, several studies also analyzed the learning curves of TAMIS and TEM, reporting an improvement of operative efficiency after $14-24^{[30]}$ and $18-31^{[31]}$ procedures for TAMIS, and after $16^{[32]}$ procedures for TEM. However, no comparison was performed in this regard.

Overall, the available studies do not show a clear superiority of TAMIS over TEM, especially in terms of resection quality, which appear similar. However, several technical advantages making TAMIS preferable are reported in the literature ${ }^{[1,2,13]}$. In particular, the use of a shorter shaft and a more flexible platform allows surgeons to reach all quadrants of the rectum, and to perform surgery in lithotomy position also in the case of anterior or lateral lesions. Moreover, TAMIS allows a faster set-up (2 $\min v$ s. up to $30-45 \mathrm{~min}^{[13]}$ ) and a $360^{\circ}$ visibility $\left(220^{\circ}\right.$ for TEM), involving the use of less expensive and more easily available equipment, such as conventional laparoscopic instruments.

\section{ROBOTIC TRANSANAL SURGERY}

The technical advantages provided by surgical robotic systems, such as stable $3 \mathrm{D}$ view and ameliorated manipulation, appeared to overcome some ergonomic limitations of TAMIS. Therefore, the same authors who had previously introduced this technique described the first combined use of robotic technology and TAMIS platforms for local transanal excision in a cadaveric model in $2011^{[33]}$, and then in a real patient in $2012^{[34]}$.

Notably, the first patient undergoing a procedure of robotic transanal surgery or robotic TAMIS (R-TAMIS) was a 58-year-old woman with a 3 -cm tubulovillous rectal adenoma with focal intramucosal carcinoma. The tumor was located at $7 \mathrm{~cm}$ from the anal verge in the left anterolateral quadrant. The patient was placed in a lithotomy position and a GelPOINT platform was used, in association with a 5-mm laparoscope introduced through one $5-\mathrm{mm}$ port and two robotic arms introduced through two 8-mm ports. A full thickness 
resection was performed and the wall defect was closed using a running barbed suture. However, already in this first case report, the authors underlined the high direct cost of the procedure, $\$ 1500$, and suggested the use of (R-TAMIS) in complex cases where TEM or conventional TAMIS, often indicated as laparoscopic TAMIS (L-TAMIS) ${ }^{[2]}$, were not possible.

Since 2012, several studies reporting the outcomes of R-TAMIS were published, but they included many case reports and small series of patients ${ }^{[2,35-41]}$. The largest series was published by Tommasi et al ${ }^{[40]}$ in 2019 and included overall 58 patients. Surgery was performed using a Da Vinci Si system in 40 cases (69\%) and a Da Vinci Xi system in 18 cases (31\%), whereas a GelPOINT platform was employed in all procedures. A 15-mmHg pneumorectum was created using conventional laparoscopic insufflation systems or an Airseal system. Robotic operative arms were placed at 4 and 8 o'clock positions, with a $0^{\circ}$ camera at 12 o'clock. A full-thickness resection was performed for 28 cancers (48.3\%), 18 adenomas (31\%), 11 carcinoids (19\%), and 1 GIST (1.7\%), and no conversion was reported. The mean console time was $66.2 \mathrm{~min}$ (range: $17-$ $180 \mathrm{~min}$ ), with significantly shorter mean operative time for Xi robot (38.7 $\mathrm{min} v \mathrm{~s} .78 .5 \mathrm{~min}, P=0.00003$ ). Complication rate was $10.3 \%$ and overall 52 patients (89.7\%) were discharged the same day of surgery. The mean specimen size was $3.3 \mathrm{~cm}$ (range: $1.3-8.2 \mathrm{~cm}$ ). There was no specimen fragmentation in 57 cases (98.3\%) and negative resection margins in 55 (94.8\%). R-TAMIS proved curative in 51 patients (88\%), while 7 patients (12\%) needed additional therapy. Finally, the authors generically concluded for the feasibility of R-TAMIS and underlined satisfying oncologic results and better ergonomics.

Some useful data are also provided by the second largest series found about R-TAMIS, published by Liu et $a l^{[36]}$ in 2018 and including 34 patients. All cases reported were performed using a Da Vinci Xi technology and a GelPOINT platform. Surgery was performed for benign lesions in 22 cases (64.7\%) and for malignant lesions in 11 cases $(32.3 \%)$. In $94 \%$ of cases $(n=32)$, patients were placed in a lithotomy position. The mean distance of rectal lesions from the dentate line was $8.6 \mathrm{~cm}$ (range: $2-15 \mathrm{~cm}$ ), with a mean maximum diameter of $2.6 \mathrm{~cm}$ (range: 0.5-4.5 cm). The overall operative time was $100 \pm 70$ min (mean \pm $\mathrm{SD}$ ), including a docking time of $25 \pm 14 \mathrm{~min}($ mean $\pm \mathrm{SD}$ ) and a console time of $76 \pm 67$ min (mean $\pm \mathrm{SD}$ ). No intraoperative complication and no conversion were reported. The postoperative complication rate was $3 \%$ and the mean hospital stay was $1.18( \pm 0.83)$ days. Full-thickness Ro resection was achieved in $97 \%$ of patients $(n=33)$, three patients were upstaged to T2-stage and underwent anterior resection, and one patient was staged T3. Moreover, the univariate analysis of operative time predictors showed that severe obesity [body mass index (BMI) > 35] was a positive predictor of total operative time and console time, probably because of a narrow space between the legs, whereas specimen size was a positive predictor of total operative time. Finally, the authors concluded that R-TAMIS was safe for lesions located within up to $15 \mathrm{~cm}$ from the dentate line and sizing up to $5.5 \mathrm{~cm}$, and that a $\mathrm{BMI}>35$ was a significant predictor of a longer and more challenging operation.

At least three further series with more than 10 patients were also published, one by Huang et al. ${ }^{[41]}$ in 2019 including 23 patients, one by Gómez Ruiz et al ${ }^{[37]}$ in 2017 including patients, and one by Hompes et al. ${ }^{[39]}$ in 2014 including 16 patients In the first study, robotic procedures were performed in a prone jackknife position, whereas, in the latter two, all procedures were performed using a lithotomy position. Note that Hompes et al. ${ }^{[39]}$ reported the use of a glove port, made up of a surgical glove positioned transanally with ports inserted through the glove's fingers.

Moreover, in 2019, Lee et al. ${ }^{[2]}$ published a study including 19 patients undergoing R-TAMIS and reported that patients with anterior and lateral lesions ( $83.3 \%$ of overall included patients) were operated in a prone position in order to reduce the conflict among robotic arms, whereas the lithotomy position was used only for posterior lesions. 


\section{L-TAMIS VS. R-TAMIS}

Robotic transanal surgery might offer several advantages compared to conventional TAMIS. Notably, it might increase the possibility of resecting rectal lesions located in difficult sites, reducing the need for proctectomy, as well as it might make surgical wound repair easier.

However, only a few studies designed to compare the outcomes of conventional and robotic TAMIS are available in the literature. The most relevant of these is a retrospective study published by Lee et al. ${ }^{[2]}$ in 2019, comparing the results of 21 patients undergoing conventional TAMIS (indicated as L-TAMIS) and 19 patients undergoing R-TAMIS. Overall, no significant difference was found in terms of perioperative outcomes (notably: total operative time, blood loss, postoperative complications, and length of hospital stay) and pathologic findings. The only significant difference was represented by direct costs, which were higher in the robotic group ( $\$ 3562$ for L-TAMIS vs. $\$ 4441$ for R-TAMIS, $P=0.04$ ).

\section{TRANSANAL TOTAL MESORECTAL EXCISION}

The latest development of the transanal approach to rectal cancer is represented by transanal total mesorectal excision (TaTME). Indeed, laparoscopic rectal surgery may be challenging because of patientand tumor-related factors. Male obese patients often show a very limited surgical field ${ }^{[42,43]}$, anterior rectal tumors appear to have a higher rate of positive resection margins ${ }^{[43,4]}$, and determining the distance between rectal tumor and distal staple line is often difficult ${ }^{[42]}$.

TaTME is a hybrid surgical technique employed for low rectal cancer combining a laparoscopic dissection for colonic mobilization and a mesorectal excision performed using a transanal approach through a GelPOINT platform or a rigid proctoscope. These approaches may be sequential or simultaneous, the specimen is generally extracted through the anus, and a manual coloanal anastomosis is finally performed ${ }^{[45]}$. Several clinical and pathological factors are considered to indicate a transanal approach in the case of rectal cancer: male gender, narrow and/or deep pelvis, BMI $>30 \mathrm{~kg} / \mathrm{m}^{2}$, prostatic hypertrophy, tumor located at less than $12 \mathrm{~cm}$ from the anal verge, tumor size $>4 \mathrm{~cm}$, and tissue alteration following radiotherapy ${ }^{[46]}$.

Sylla et al. ${ }^{[47]}$ performed the first clinical case of TaTME in 2010. In 2016, Deijen et al. ${ }^{[48]}$ published a systematic review including overall 794 patients with rectal cancer undergoing this technique. The mean operative time was $244 \mathrm{~min}$ and the TME specimen was complete in $87 \%$ of procedures. Major postoperative complications occurred in $11.5 \%$ of patients and anastomotic leak in $5.7 \%$. Local recurrence rate was $8.1 \%$ at 18.9 months. A volume effect was also shown, with high-volume centers ( $>30$ cases) having higher TME quality, lower rate of positive circumferential resection margin (CRM), and lower rate of major complications.

In 2017, Penna et al. ${ }^{[49]}$ analyzed TaTME short-term outcomes using the data of an international registry including 720 patients. TME was complete in $85 \%$ of cases, had minor defects in $11 \%$ of cases, and had major defects in $4 \%$. The rate of $\mathrm{R} 1$ resection was $2.7 \%$. Among the risk factors of suboptimal TME, perforation, and/or R1 resection, the authors also identified a laparoscopic transabdominal posterior dissection to less than $4 \mathrm{~cm}$ from the anal verge.

In 2018, Jiang et al ${ }^{[50]}$ published a systematic review of studies comparing TaTME and laparoscopic TME. They included 762 patients overall operated for cancer of the middle and lower rectum, and showed a significant difference in terms of positive CRM in favor of TaTME, whereas positive distal resection margin and TME quality were similar.

\section{ROBOTIC TATME}

TaTME has also been performed using robotic technology, being indicated as robotic TaTME or roboticassisted transanal TME (RATS-TME). However, the studies on this subject currently available in the literature are characterized by a limited number of patients ${ }^{[51-55]}$. 
Notably, one of the largest was published in 2020 by Hu et al ${ }^{[56]}$ and included only 20 patients. Eleven of them $(55 \%)$ were operated for mid rectal cancer and nine (45\%) for low rectal cancer. The distance between tumor to anal verge was $6.0 \pm 2.7 \mathrm{~cm}$ (mean $\pm \mathrm{SD}$ ), the operative team was $172.3 \pm 24.2$ min (mean $\pm \mathrm{SD}$ ), and the blood loss $82.0 \pm 107.1 \mathrm{~mL}$ (mean $\pm \mathrm{SD}$ ). No conversion was reported, the postoperative complication rate was $35 \%$, and the length of hospital stay was $8.8 \pm 4.2$ days. In $90 \%$ of cases, TEM was complete, and the number of lymph nodes harvested per specimen was $18.7 \pm 6.3$ (mean \pm SD). The distal margin length was $3.1 \pm 1.3 \mathrm{~cm}$. Positive CRM was found in $15 \%$ of cases $(n=3)$.

\section{CONCLUSION}

TAMIS represents a valid therapeutic option in the surgical treatment of benign and malignant lesions of the rectum compared to TEM. Robotic transanal surgery soon developed after the introduction of TAMIS and consists in associating the use of robotic surgical systems to transanal disposable platforms. It proved to be safe and effective, but the data currently available in the literature do not show clear statistical advantages compared to conventional TAMIS. Therefore, further studies will be necessary.

\section{DECLARATIONS}

\section{Authors' contributions}

Conception: Genova P, Memeo R, Brunetti F

Literature review: Genova $\mathrm{P}$

Writing: Genova P

Revision: Genova P, Memeo R, Brunetti F

\section{Availability of data and materials}

Not applicable.

\section{Financial support and sponsorship}

None.

\section{Conflicts of interest}

All authors declared that there are no conflicts of interest.

\section{Ethical approval and consent to participate}

Not applicable.

\section{Consent for publication}

Not applicable.

\section{Copyright}

(c) The Author(s) 2020.

\section{REFERENCES}

1. Rai V, Mishra N. Transanal approach to rectal polyps and cancer. Clin Colon Rectal Surg 2016;29:65-70.

2. Lee SG, Russ AJ, Casillas MA. Laparoscopic transanal minimally invasive surgery (L-TAMIS) versus robotic TAMIS (R-TAMIS): short-term outcomes and costs of a comparative study. Surg Endosc 2019;33:1981-7.

3. Garcia-Aguilar J, Mellgren A, Sirivongs P, Buie D, Madoff RD, et al. Local excision of rectal cancer without adjuvant therapy: a word of caution. Ann Surg 2000;231:345-51.

4. Paty PB, Nash GM, Baron P, Zakowski M, Minsky BD, et al. Long-term results of local excision for rectal cancer. Ann Surg 2002;236:529-30.

5. Buess G, Theiss R, Hutterer F, Pichlmaier H, Pelz C, et al. Transanal endoscopic surgery of the rectum-testing a new method in animal experiments. Leber Magen Darm 1983;13:73-7. (in German)

6. Gordon PH, Nivatvongs S. Principles and practice of surgery for the colon, rectum, and anus. CRC Press; 2007. 
7. Christoforidis D, Cho HM, Dixon MR, Mellgren AF, Madoff RD, et al. Transanal endoscopic microsurgery versus conventional transanal excision for patients with early rectal cancer. Ann Surg 2009;249:776-82.

8. Clancy C, Burke JP, Albert MR, O'Connell PR, Winter DC. Transanal endoscopic microsurgery versus standard transanal excision for the removal of rectal neoplasms: a systematic review and meta-analysis. Dis Colon Rectum 2015;58:254-61.

9. De Graaf EJR, Burger JWA, Van Ijsseldijk ALA, Tetteroo GWM, Dawson I, et al. Transanal endoscopic microsurgery is superior to transanal excision of rectal adenomas. Colorectal Dis 2011;13:762-7.

10. Han Y, He YG, Lin MB, Zhang YJ, Lu Y, et al. Local resection for rectal tumors: comparative study of transanal endoscopic microsurgery vs. conventional transanal excision - the experience in China. Hepatogastroenterology 2012;59:2490-3.

11. Atallah S, Albert M, Larach S. Transanal minimally invasive surgery: a giant leap forward. Surg Endosc 2010;24:2200-5.

12. Martin-Perez B, Andrade-Ribeiro GD, Hunter L, Atallah S. A systematic review of transanal minimally invasive surgery (TAMIS) from 2010 to 2013. Tech Coloproctol 2014;18:775-88.

13. deBeche-Adams T, Hassan I, Haggerty S, Stefanidis D. Transanal minimally invasive surgery (TAMIS): a clinical spotlight review. Surg Endosc 2017;31:3791-800.

14. deBeche-Adams T, Nassif G. Transanal minimally invasive surgery. Clin Colon Rectal Surg 2015;28:176-80.

15. Serra-Aracil X, Mora-Lopez L, Alcantara-Moral M, Corredera-Cantarin C, Gomez-Diaz C, et al. Atypical indications for transanal endoscopic microsurgery to avoid major surgery. Tech Coloproctol 2014;18:157-64.

16. Pigalarga R, Patel NM, Rezac C. Transanal endoscopic microsurgery-assisted rectal advancement flap is a viable option for iatrogenic rectourethral fistula repair: a case report. Tech Coloproctol 2011;15:209.

17. Duek SD, Gilshtein H, Khoury W. Transanal endoscopic microsurgery: also for the treatment of retrorectal tumors. Minim Invasive Ther Allied Technol 2014;23:28-31.

18. Bochove-Overgaauw DM, Beerlage HP, Bosscha K, Gelderman WAH. Transanal endoscopic microsurgery for correction of rectourethral fistulae. J Endourol 2006;20:1087-90.

19. Smith LE, Ko ST, Saclarides T, Caushaj P, Orkin BA, et al. Transanal endoscopic microsurgery. Dis Colon Rectum 1996;39:S79-S84.

20. Benson AB, Venook AP, Al-Hawary MM, Cederquist L, Chen YJ, Ciombor KK, et al. Rectal cancer, version 3.2019, NCCN clinical practice guidelines in oncology. J National Comprehensive Cancer Network 2019;16:874-901.

21. Hahnloser D, Cantero R, Salgado G, Dindo D, Rega D, et al. Transanal minimal invasive surgery for rectal lesions: should the defect be closed? Colorectal Dis 2015;17:397-402.

22. Albert MR, Atallah SB, deBeche-Adams TC, Izfar S, Larach SW. Transanal minimally invasive surgery (TAMIS) for local excision of benign neoplasms and early-stage rectal cancer: efficacy and outcomes in the first 50 patients. Dis Colon Rectum 2013;56:301-7.

23. Mendes CRS, Ferreira LSdM, Sapucaia RA, Lima MA, Araujo SEA. Transanal minimally-invasive surgery (TAMIS): technique and results from an initial experience. J Coloproctol (Rio de Janeiro) 2013;33:191-5.

24. Van den Boezem P, Kruyt PM, Stommel M, Morales RT, Cuesta M, et al. Transanal single-port surgery for the resection of large polyps. Dig Surg 2011;28:412-6.

25. Molina G, Bordeianou L, Shellito P, Sylla P. Transanal endoscopic resection with peritoneal entry: a word of caution. Surg Endosc 2016;30:1816-25.

26. Mege D, Bridoux V, Maggiori L, Tuech JJ, Panis Y. What is the best tool for transanal endoscopic microsurgery (TEM)? A case-matched study in 74 patients comparing a standard platform and a disposable material. Int J Colorectal Dis 2017;32:1041-5.

27. Melin AA, Kalaskar S, Taylor L, Thompson JS, Ternent C, et al. Transanal endoscopic microsurgery and transanal minimally invasive surgery: is one technique superior? Am J Surg 2016;212:1063-7.

28. Lee L, Edwards K, Hunter IA, Hartley JE, Atallah SB, et al. Quality of local excision for rectal neoplasms using transanal endoscopic microsurgery versus transanal minimally invasive surgery: a multi-institutional matched analysis. Dis Colon Rectum 2017;60:928-35.

29. Van den Eynde F, Jaekers J, Fieuws S, D'Hoore AM, Wolthuis AM. TAMIS is a valuable alternative to TEM for resection of intraluminal rectal tumors. Tech Coloproctol 2019;23:161-6.

30. Lee L, Kelly J, Nassif GJ, Keller D, Debeche-Adams TC, et al. Establishing the learning curve of transanal minimally invasive surgery for local excision of rectal neoplasms. Surg Endosc 2018;32:1368-76.

31. Clermonts S, van Loon YT, Stijns J, Pottel H, Wasowicz DK, et al. The effect of proctoring on the learning curve of transanal minimally invasive surgery for local excision of rectal neoplasms. Tech Coloproctol 2018;22:965-75.

32. Helewa RM, Rajaee AN, Raiche I, Williams L, Paquin-Gobeil M, et al. The implementation of a transanal endoscopic microsurgery programme: initial experience with surgical performance. Colorectal Dis 2016;18:1057-62.

33. Atallah S, Albert M, deBeche-Adams T, Larach S. Robotic transanal minimally invasive surgery in a cadaveric model. Tech Coloproctol 2011;15:461-4.

34. Atallah S, Parra-Davila E, DeBeche-Adams T, Albert M, Larach S. Excision of a rectal neoplasm using robotic transanal surgery (RTS): a description of the technique. Tech Coloproctol 2012;16:389-92.

35. Warren C, Hamilton A, Stevenson A. Robotic transanal minimally invasive surgery (TAMIS) for local excision of rectal lesions with the da Vinci Xi (dVXi): technical considerations and video vignette. Tech Coloproctol 2018;22:529-33.

36. Liu S, Suzuki T, Murray BW, Parry L, Johnson CS, et al. Robotic transanal minimally invasive surgery (TAMIS) with the newest robotic surgical platform: a multi-institutional North American experience. Surg Endosc 2019;33:543-8.

37. Gómez Ruiz M, Cagigas Fernández C, Alonso Martín J, Cristobal Poch L, Manuel Palazuelos C, et al. Robotic assisted transanal polypectomies: is there any indication? Cir Esp 2017;95:601-9.

38. Erenler I, Aytac E, Bilgin IA, Baca B, Hamzaoglu I, et al. Robotic transanal minimally invasive surgery (R-TAMIS) with the da Vinci Xi System-a video vignette. Colorectal Dis 2017;19:401.

39. Hompes R, Rauh SM, Ris F, Tuynman JB, Mortensen NJ. Robotic transanal minimally invasive surgery for local excision of rectal neoplasms. Br J Surg 2014;101:578-81. 
40. Tomassi MJ, Taller J, Yuhan R, Ruan JH, Klaristenfeld DD. Robotic transanal minimally invasive surgery for the excision of rectal neoplasia: clinical experience with 58 consecutive patients. Dis Colon Rectum 2019;62:279-85.

41. Huang YJ, Huang YM, Wang WL, Tong YS, Hsu W, et al. Surgical outcomes of robotic transanal minimally invasive surgery for selected rectal neoplasms: a single-hospital experience. Asian J Surg 2019;43:290-6.

42. Velthuis S, Van den Boezem PB, Van der Peet DL, Cuesta MA, Sietses C. Feasibility study of transanal total mesorectal excision. Br J Surg 2013;100:828-31.

43. Araujo SE, Crawshaw B, Mendes CR, Delaney CP. Transanal total mesorectal excision: a systematic review of the experimental and clinical evidence. Tech Coloproctol 2015;19:69-82.

44. Rouanet P, Mourregot A, Azar CC, Carrere S, Gutowski M, et al. Transanal endoscopic proctectomy: an innovative procedure for difficult resection of rectal tumors in men with narrow pelvis. Dis Colon Rectum 2013;56:408-15.

45. Westwood DA, Cuda TJ, Hamilton AR, Clark D, Stevenson AR. Transanal total mesorectal excision for rectal cancer: state of the art. Tech Coloproctol 2018;22:649-55.

46. Motson RW, Whiteford MH, Hompes R, Albert M, Miles WF; Expert Group. Current status of trans-anal total mesorectal excision (Ta TME) following the Second International Consensus Conference. Colorectal Dis 2016;18:13-8.

47. Sylla P, Rattner DW, Delgado S, Lacy AM. NOTES transanal rectal cancer resection using transanal endoscopic microsurgery and laparoscopic assistance. Surg Endosc 2010;24:1205-10.

48. Deijen CL, Tsai A, Koedam TWA, Helbach MV, Sietses C, Lacy AM, et al. Clinical outcomes and case volume effect of transanal total mesorectal excision for rectal cancer: a systematic review. Techniques in coloproctology 2016;20:811-24.

49. Penna M, Cunningham C, Hompes R. Transanal total mesorectal excision: why, when, and how. Clin Colon Rectal Surg 2017;30:339-45.

50. Jiang HP, Li YS, Wang B, Wang C, Liu F, et al. Pathological outcomes of transanal versus laparoscopic total mesorectal excision for rectal cancer: a systematic review with meta-analysis. Surg Endosc 2018;32:2632-42.

51. Verheijen PM, Consten EC, Broeders IA. Robotic transanal total mesorectal excision for rectal cancer: experience with a first case. Int J Med Robot 2014;10:423-6.

52. Huscher CG, Bretagnol F, Ponzano C. Robotic-assisted transanal total mesorectal excision: the key against the Achilles' heel of rectal cancer? Ann Surg 2015;261:e120-1.

53. Gómez Ruiz M, Parra IM, Palazuelos CM, Martín JA, Fernández CC, et al. Robotic-assisted laparoscopic transanal total mesorectal excision for rectal cancer: a prospective pilot study. Dis Colon Rectum 2015;58:145-53.

54. Atallah S, Martin-Perez B, Pinan J, Quinteros F, Schoonyoung H, et al. Robotic transanal total mesorectal excision: a pilot study. Tech Coloproctol 2014;18:1047-53.

55. Kuo LJ, Ngu JC, Tong YS, Chen CC. Combined robotic transanal total mesorectal excision (R-taTME) and single-site plus one-port (R-SSPO) technique for ultra-low rectal surgery - initial experience with a new operation approach. Int J Colorectal Dis 2017;32:249-54.

56. Hu JM, Chu CH, Jiang JK, Lai YL, Huang IP, et al. Robotic transanal total mesorectal excision assisted by laparoscopic transabdominal approach: a preliminary twenty-case series report. Asian J Surg 2020;43:330-8. 